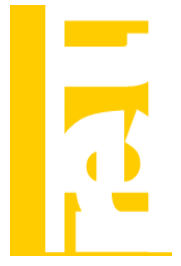

\title{
OBITUARIO: \\ LUIS TOHARIA IN MEMORIAM
}

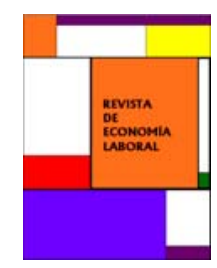

\author{
Carlos García-Serrano*, Juan Francisco Jimeno** \\ Miguel Ángel Malo ${ }^{\dagger}$ José Ignacio Pérez-Infante \\ *Universidad de Alcalá, **Banco de España \\ †Universidad de Salamanca, $¥$ Comisión Consultiva Nacional de Convenios Colectivos
}

Luis, nuestro compañero, amigo y maestro, falleció el viernes 3 de febrero, unos días después de cumplir 61 años, tras luchar con entereza y ánimo contra la enfermedad durante dos años y medio.

Referirse a Luis Toharia es hablar de la Economía Laboral en España, puesto que desde hace tres décadas ha ejercido una profunda influencia en la investigación sobre este ámbito del conocimiento a través de sus aportaciones académicas, su participación en tareas de asesoría a diferentes Administraciones Públicas, la formación de investigadores y el impulso de actividades para facilitar el encuentro y la interacción de los investigadores españoles en temas laborales.

Luis Toharia ha tenido una carrera investigadora y docente larga y fecunda. Se licenció en Ciencias Económicas por la Universidad Autónoma de Madrid en 1973 y obtuvo el título de Doctor (Ph.D.) en Economía por el Massachusetts Institute of Technology (M.I.T.) en 1979, incorporándose posteriormente a la Universidad de Alcalá, donde ejerció la docencia, siendo uno de los profesores más reconocidos de la Facultad de Económicas, hasta el día de su jubilación.

En cuanto a su obra, su investigación ha estado siempre centrada en temas de gran relevancia y calado social, sin descuidar nunca el rigor y un tratamiento respetuoso y profundo de los datos que distingue especialmente sus trabajos. Ha dejado su impronta en muchas áreas, influyendo en diferentes momentos en la elaboración de las políticas laborales y sociales. Posiblemente por haber influido sobre los propios datos con los que investigadores y analistas estudian el mercado de trabajo, su aportación de mayor calado tiene que ver con su análisis continuado desde principios de la década de los ochenta de la

(C) Revista de Economía Laboral 
medición del empleo y del desempleo. Sus trabajos sobre la calidad de los datos de la Encuesta de Población Activa y la comprensión profunda que ha aportado de la información contenida en los datos administrativos de demandantes de empleo y del paro registrado, han supuesto avances cruciales en el conocimiento y la comprensión de la realidad laboral española. Su aportación a esta cuestión se ha realizado colaborando muy de cerca en la construcción de dichas bases de datos, con organismos como el Instituto Nacional de Estadística, el Servicio Público de Empleo Estatal y el Ministerio de Trabajo.

A lo largo de los años, Luis Toharia ha mostrado una generosidad extraordinaria formando a varias generaciones de economistas dedicados al estudio del mercado de trabajo, dirigiendo tesis doctorales, constituyendo un equipo de investigadores en la Universidad de Alcalá y colaborando con numerosos colegas en otras universidades, con los que ha desarrollado líneas de investigación de gran relevancia. Su capacidad para formar nuevos especialistas se ha complementado con la creación de espacios para la discusión y la colaboración de los especialistas en Economía Laboral. En este sentido cabe destacar que promovió directa y personalmente la creación y puesta en marcha de las Jornadas de Economía Laboral a partir de 1995 y la creación de la Asociación Española de Economía del Trabajo en el año 2005. Precisamente la creación de la Revista de Economía Laboral (junto con Joaquín Lorences, Miguel Ángel Malo y Carlos Peraita) formó parte de sus esfuerzos para crear espacios de discusión sobre los problemas del mercado de trabajo y de las relaciones laborales.

$\mathrm{Su}$ intensa carrera muestra una dedicación, una capacidad de trabajo y una calidad realmente inusuales. Sus constantes aportaciones y el ejemplo permanente de su buen saber hacer en el tratamiento de los datos supuso el lanzamiento, la consolidación y el desarrollo de los estudios sobre el mercado de trabajo español, que han supuesto una transferencia, significativa y de la mayor importancia, de conocimientos desde la universidad a la sociedad española, aparte de su inestimable labor como formador de nuevos investigadores. La calidad de su trabajo, su implicación en los problemas del mercado laboral español, su honestidad intelectual, su amable magisterio y su generosidad son ejemplos a seguir para las nuevas generaciones de investigadores laborales en España. 